\title{
Right Seminal Vesicle
}

National Cancer Institute

\section{Source}

National Cancer Institute. Right Seminal Vesicle. NCI Thesaurus. Code C128611.

The seminal gland that is located to the anatomical right of the bladder. 